\title{
RICHARD LINDAU Y EL MUSEO DE ARTE JAPONÉS DE BARCELONA
}

\author{
RICARD BRU TURULL
}

\begin{abstract}
Richard Lindau residió como diplomático en Japón entre 1866 y 1868, durante los años de transición entre el shogunato Tokugawa y el nuevo sistema imperial Meiji. Lindau estuvo en el archipiélago nipón en el momento oportuno para adquirir una excepcional colección de arte japonés. Trasladado a Barcelona en 1876 como cónsul de Alemania, Lindau ofreció la colección al público abriendo su residencia y anunciándola como Museo Japonés. Este artículo recupera la historia de la colección olvidada de uno de los primeros museos privados de arte japonés del sur de Europa.
\end{abstract}

Palabras clave: Museo; Coleccionismo; Colección japonesa; Japón; Japonismo.

\section{RICHARD LINDAU AND THE MUSEUM OF JAPANESE ART IN BARCELONA}

Richard Lindau resided as a diplomat in Japan between 1866 and 1868, where he acquired in Edo (Tokyo) an extensive and exceptional collection of Japanese art. After being named German consul in Barcelona (1876), Lindau offered his collection to the public by opening his residence in the centre of the city as a Japanese Museum. This paper aims to recover the history of this forgotten collection, which constituted one of the first private museums of Japanese art in Southern Europe.

Key words: Museum; Collecting; Japanese collection; Japan; Japanism.

A finales del mes de enero de 1854, simultáneamente a la llegada del comodoro Matthew C. Perry a la bahía de Edo, se inauguró en Londres, en la Gallery of the Old Society of Painters in Water Colours de Pall Mall East, una de las primeras exposiciones temporales de arte japonés organizadas en Europa. Dos meses antes de que Japón firmara el tratado de Kanagawa, con el que se puso fin a dos siglos de aislamiento nacional, Londres mostraba a sus habitantes una colección de artesanías japonesas que fueron descritas como piezas únicas; a singular cargo of curiosities has just been brought to the metropolis from Japan, one of the most sealed countries of the globe ${ }^{1}$. La exposición marcó un punto de inflexión entre la llegada con cuentagotas de arte japonés a través de Holanda y la pasión cada vez más extendida por el coleccionismo en torno

1 The Illustrated London News, 4-II-1854: 97. 
al fenómeno del Japonismo y en torno a personajes como los hermanos Goncourt, Philippe Burty, Zacharie Astruc, Louis Gonse, Siegfried Bing o Hayashi Tadamasa.

Sin embargo, a pesar de contadas excepciones, se puede afirmar que no fue hasta inicios de la década de 1860, cuando tanto en Europa como en Estados Unidos se formaron las primeras grandes colecciones de arte japonés, muchas de las cuales, diseminadas a inicios del siglo XX, quedaron en el olvido. Es en este contexto que, de entre las piezas japonesas que empezaron a llegar a la España de la década de 1870, Barcelona vio nacer una de las primeras colecciones de arte japonés del sur de Europa abiertas al público: el Museo de Objetos Japoneses del cónsul Herr Richard Lindau².

\section{Rudolph Lindau en el Japón bakumatsu}

Herr Richard Lindau (1831-1900), fundador del Museo de Objetos Japoneses, también conocido como Museo Japonés de Barcelona, era el tercero de cuatro hermanos: Anna (1828-1880), Rudolph (1829-1910) y Paul (1839-1919). Cuatro hermanos que, cada uno con una trayectoria distinta, difundieron el apellido Lindau por Europa como el de una familia de intelectuales única y singular. Paul, escritor, fue el que seguramente consiguió más renombre internacional gracias a una extensa y rica obra literaria. Anna, íntima amiga de Karl Marx, mujer vital y apasionada de la música, fue la madre de Annie Vivanti, poetisa de gran fama en Italia. Pero fue Rudolph, diplomático, quien más influencia ejerció en Richard Lindau, nuestro biografiado.

Rudolph Lindau nació en Gardelegen el 10 de octubre de 1829. Hombre de vasta cultura, su prestigio se forjó a raíz de una extensa obra escrita y una amplia experiencia en el campo de la diplomacia. Si Anna y Paul dirigieron sus vidas hacia Suiza, Inglaterra y Alemania, Rudolph empezó un camino distinto formándose en la Universidad de Montpellier. De joven se introdujo en el ambiente de la diplomacia francesa llegando al cargo de representante del gobierno prusiano, posteriormente alemán, en Francia, Suiza y Turquía. Estos cargos los ocupó antes de la década de 1860, cuando muchas de las miradas diplomáticas se trasladaron hacia el Asia Oriental, hacia la China y especialmente el Japón.

Japón, que justo acababa de firmar los primeros tratados internacionales en 1858, era en esas fechas uno de los países más atractivos, complejos y desconocidos y, como tal, fascinó a los hermanos Lindau. Tan pronto como el japonólogo Léon de Rosny creó en París la Société d'Ethongraphie Americaine et Orientale, en 1859, Rudolph Lindau entró en la sociedad como miembro titular. Ese mismo año, Lindau, Rudolph, llegó a Edo, la antigua Tokio, guiado por el secretario de la legación norteamericana, Henry Heusken³ .

Esos fueron años difíciles. Japón vivía entonces un intenso debate entre los partidarios de abrir los puertos al mundo y aquellos que preferían optar por una política rígida de rechazo a las demandas occidentales. Fue especialmente conflictivo el periodo conocido como bakumatsu, situado entre la llegada del comodoro Perry, en 1853, y el inicio de la restauración imperial, en 1868. Durante el bakumatsu, los diplomáticos y los primeros comerciantes europeos y america-

\footnotetext{
2 Muchas de las colecciones de arte japonés existentes en la España del 1900 se crearon de forma gradual, mayoritariamente en Barcelona, durante el último cuarto del siglo XIX. Si comparamos este hecho con lo que sucedió, por ejemplo, en París o en Londres, veremos cómo las colecciones francesas e inglesas empezaron a constituirse en fechas anteriores, a partir de finales de la década de 1850, a raíz de la firma de los primeros tratados comerciales con Japón y gracias a la apertura de los primeros establecimientos de arte nipón en la década de 1860. Sobre la colección Lindau en el contexto del coleccionismo de arte japonés en Cataluña, véase: Bru, 2004: 233-257.

${ }^{3}$ Lindau, 1864: 4. El libro Un voyage autour du Japon, fue el fruto de sus dos primeras estancias en Japón, en 1859 y $1861-62$.
} 
nos vivieron en primera persona la beligerancia de una población que los recibió con la hostilidad como intrusos en tierra prohibida: Heusken, el compañero de Lindau, murió asesinado poco tiempo después de su llegada al archipiélago. Rudolph Lindau, sin embargo, no hizo marcha atrás y, después de un segundo viaje a Japón entre 1861 y 1862, se estableció en 1865 como cónsul en Yokohama. Lindau era consciente de que la historia de Japón se encontraba en un momento crucial:

J'avais vu à une époque des plus intéressantes de son histoire, au commencement de la grande révolution causée par l'intrusion de l'élément étranger dans la société japonaise et que je quittai au moment où l'assassinat de M. Lennox Richardson allait lui attirer des châtiments sévères de la part de l'Angleterre et précipiter les changements politiques qui se préparaient depuis trois ans. Cette révolution n'est pas encore terminée; cependant, quel qu'en soit l'issue, "l'empire du soleil naissant" restera éternellement beau, et la vigoureuse race qu'il nourrit conservera les qualités éminentes qui font d'elle la première et la plus intéressante nation de l'extrême Orient ${ }^{4}$.

Suponemos que el hermano menor de Rudolph, Richard, que entonces se encontraba en París, iba siguiendo de cerca las aventuras, las experiencias y las noticias que le iban llegando, tanto de primera mano como a través de los artículos que Rudolph publicaba en la Revue des Deux Mondes. Reflexiones como las que hacía Rudolph, y la misma posibilidad de conocer un país con tan profundas transformaciones políticas y sociales, estamos convencidos de que fascinaron a un joven diplomático como era Richard. Así lo creemos porque en enero de 1862, durante la segunda estancia de su hermano en Oriente, Richard entró a formar parte de la misma Société d'Ethnographie Americaine et Orientale, donde fue nombrado miembro titular ${ }^{5}$. Poco después partió hacia Japón. De esta forma, los dos hermanos Lindau, primero Rudolph como cónsul de Suiza en Yokohama (1865-1866), y posteriormente Richard, como vicecónsul de Prusia en Nagasaki (1866-1868), presenciaron uno de los momentos más cruciales de la historia moderna de Japón: el final del bakumatsu y el inicio de restauración imperial Meiji.

\section{Richard Lindau: entre Japón y Barcelona}

La trayectoria profesional de Richard Lindau, nacido en la población de Genthin el 7 de mayo de 1831, fue larga y diversa. Pasó su juventud en París, donde estuvo varios años trabajando como músico y profesor de canto. Ese trabajo lo compaginó con la formación diplomática antes de ser enviado como cónsul a Japón, y posteriormente a Francia y a España.

The Chronicle and Directory for China, Japan and the Philippines for 1867 es por ahora el principal documento que nos sirve para certificar que Richard Lindau llegó a Japón antes de la restauración Meiji, probablemente en 1866, para ocupar el cargo de vicecónsul de Prusia en Nagasaki, con sede en el distrito de Higashiyamate, bajo las órdenes de los cónsules de Prusia en Yokohama, M. von Brandt (1867) y M.H. Cildemeister (1868)6. Además, Lindau también entró a trabajar como socio de la empresa que Thomas y John G. Walsh tenían establecida en Nagasaki desde 1862 (Walsh \& Co $)^{7}$. Richard Lindau vivió en Japón, en Nagasaki, unos dos

\footnotetext{
${ }^{4}$ Lindau, 1864: 311-312.

5 Actes de la Société d'Ethnographie Americaine et Orientale, vol. III, 1862: 5.

${ }^{6}$ The Chronicle and Directory for China, Japan and the Philippines for 1867-1868, Hong kong, 1867. Historical documents relating to Japan in foreign countries, vol. 11, Tokio, 1968: 113. Meissner, 1961: 25.

${ }^{7}$ La parcela núm. 12 del distrito de Higashiyamate, donde se situaba el consulado de Prusia, era inicialmente propiedad de Richard J. Waksh. Es probable que Lindau trabajase con Thomas y John G. Walsh, primer cónsul de
} 
años, hasta septiembre de 1868, fecha en que, después de una breve estancia en Edo, volvió a Europa e inició una serie de viajes por el Pacífico, las islas Fiji, Hawaii y Australia. Aunque tenemos constancia de algunas otras estancias posteriores en Japón ${ }^{8}$ actuando probablemente como socio de la empresa Alt \& Co., al cabo de poco tiempo fue nombrado cónsul de Alemania en Marsella, posteriormente en Bayona y finalmente en Barcelona.

El 19 de julio de 1876 Herr Richard Lindau fue nombrado, en el Palacio Mayor de Madrid, cónsul de Alemania en Barcelona en sustitución de George Vollmar, quien hasta entonces ejerció las mismas funciones ${ }^{9}$. Desde ese momento, Lindau y el vicecónsul Charles Weiss, se establecieron en la Ciudad Condal, en la sede del cuerpo consular de la confederación de Alemania y Prusia, situada en la calle Nou de Sant Francesc, cerca de la Rambla.

Lindau se estableció en Barcelona, donde pasó el resto de su vida, probablemente hasta su fallecimiento en 1900. Era evangelista protestante y tuvo tres hijos y una hija con su pareja sentimental, María Sauce Pérez ${ }^{10}$. Tenemos pocas noticias de su vida privada y de su actividad diplomática en España, a excepción del polémico tratado comercial firmado con Alemania en $1894^{11}$. Sin embargo, sabemos que Richard Lindau, después de una breve licencia y traslado como Cónsul General honorario de España en Berlín en 1887, el mes de junio de 1888 fue ascendido a Cónsul General de Alemania en España, justo después de inaugurarse la Exposición Universal de Barcelona ${ }^{12}$.

Richard Lindau vivió muy próximo a la música. Antes de consolidar su trayectoria como diplomático, Lindau había aparecido a menudo por París actuando como músico, como tenor y como poeta. En Magdeburg, ciudad natal de sus hermanos Paul y Anna, y ciudad de formación de Rudolph y del mismo Richard, fue donde residió temporalmente Wagner, el gran compositor, cuando Richard Lindau era aun un niño de solo tres o cuatro años. Fue una coincidencia o una premonición ya que el encuentro se repitió años mas tarde en París cuando el joven Lindau, entonces profesor de canto y cantante, mantuvo relación con Richard Wagner y su mujer. Wagner explicaba en su autobiografía el trato que tuvo con Lindau, el impertinente Lindau, decía. La relación entre los dos terminó en los tribunales porque Lindau reclamó una parte de los derechos de autor de la traducción al francés de Tannhaüser, escrita juntamente con Charles Nuitter y Edmond Roche; unos derechos que Wagner nunca quiso reconocer ${ }^{13}$.

Lindau no solo fue maestro de música en casa de Wagner, sino que varias fuentes nos informan que también fue profesor de armonía del industrial coleccionista y compositor lionés Émile Guimet, años antes de que este último viajara a Japón y se convirtiera en el fundador, en 1889,

América en Nagasaki, gracias a los contactos y a la buena amistad que estos dos últimos tenían con su hermano Rudolph. Eso mismo sucedió durante los mismos años con el prestigioso científico Gottfried Wagener. Wagener, uno de los científicos occidentales más influyentes y destacados de los primeros años de la era Meiji, llegó a Nagasaki en 1868 con el fin de trabajar en una de las fábricas de Thomas Walsh, al cual había conocido años antes en París, hacia 1862, gracias a Rudoplh Lindau. Weber, 1981: 348. Avitable, 1995: 100.

8 The Japan Weekly Mail, 26-II-1870: 71. The Japan Weekly Mail, 5-III-1870: 83. The Japan Weekly Mail, 11-I-1873: 26.

9 Archivo General del Ministerio de Asuntos Exteriores y Comercio de España, Madrid (AGMAEC), P-151, exp. 7711.

10 Agradezco estos datos biográficos a Aya Puster y Matthias Koch. La fecha de fallecimiento la extraemos de la Enciclopedia Espasa, teniendo en cuenta que los datos de la Deutsche National Bibliothek apuntan a una muerte fechada doce años más tarde, en 1912.

11 Véase una entrevista a Lindau publicada en El Heraldo de Madrid (13-VII-1894).

12 AGMAEC, P-152, exp. 7797. Archivo Diplomático y Consular de España, 16-V-1888: 177. Payno, 1889: 310.

13 Wagner, 1952: 525. Annuaire de la Société des Auteurs et Compositeurs Dramátiques, Commission des Auteurs et Compositeurs Dramatiques, París, 1867: 600. Gazette des Tribunaux, 7-III-1861. Sotheby's recientemente (venta N08698, lote 441,17-V-2010) subastó una carta autógrafa de Wagner pidiendo ayuda económica a Richard Lindau. 
de uno de los principales museos de arte oriental de Europa ${ }^{14}$. En este sentido, en ocasión de un concierto de canto ofrecido por Richard Lindau hacia 1858 en la Société philharmonique de Lyon, un joven Émile Guimet describía a Lindau, expresamente llegado desde París, como un artiste éminent; las melodías que interpretaba, de Schubert y Niedermeyer, se caracterizaban por une grande simplicité, decía Guimet, consiguiendo un effet irrésistible gracias a su voz; voix douce, pleine et sympathique ${ }^{15}$. Igualmente, varias críticas de periódicos documentan al joven Lindau como tenor especializado en lieder y canciones alemanas actuando en salas de París como mínimo entre 1855 y $1861^{16}$. A pesar de que la autobiografía de Wagner nos recuerda la nefasta relación que el compositor tuvo con Lindau, al cual describió como un pésimo cantante, este segundo nunca dejó de amar la música.

Un año después del estreno de Tannhaüser en París, el verano de 1862 la marcha del segundo acto de la ópera se pudo escuchar por primera vez en Barcelona. La melodía y el canto de Tannhaüser, que había sido traducido con la colaboración de Lindau, presagiaba la llegada del wagnerianismo y el gran interés por la música alemana que Cataluña vivió en las décadas de 1880 y 1890, un periodo en el cual Richard Lindau se convirtió en uno de los promotores de la música germana en Barcelona, tanto desde el Círculo del Gran Teatro del Liceo como desde el club Germania del Círculo Alemán, establecido en el Café Suizo ${ }^{17}$. Este café era uno de los principales puntos de encuentro de la comunidad germana de la ciudad y allí, en las tertulias del club Germania, Lindau y el compositor Engelbert Humperdinck debieron hablar y discutir sobre Wagner, sobre la música y sobre el estado de la cultura en Barcelona.

Durante la década de 1880, entre los wagnerianos barceloneses que destacaron por la defensa pública de la música alemana había muchos miembros del Círculo del Gran Teatro del Liceo: el Dr. Letamendi, Joan Goula, Josep Rodoreda y Engelbert Humperdinck, todos ellos bien conocidos por Richard Lindau ${ }^{18}$. Tanto es así que, cuando a mediados de noviembre de 1885 Humperdinck llegó por segunda vez a Barcelona para ocupar una plaza de profesor de teoría musical en el Conservatorio del Liceo, el joven compositor alemán fue introducido inicialmente en el Círculo del Liceo por el socio Richard Lindau. Lindau tenía muchos proyectos en mente: [Lindau] habla de dirigir conciertos y dirigir la orquesta en los Teatros... naturalmente peu à peu. "Espere usted", dice [Lindau], "quizás podrá encontrar aqui su suerte y empezar una buena trayectoria, todo depende de cómo se desarrollen las cosas"19. Fue precisamente durante esos años cuando el Liceo estrenó la obertura de Rienzi (1874) y las óperas Lohengrin (1882/1883), El holandés errante (1885) y Tannhäuser (1887). En junio de 1883, unos días después de las actuaciones de Lohengrin, Engelbert Humperdinck, recién llegado a Barcelona, describió a Richard Lindau, tal vez con cierta ironía, como compositor, navegante y viejo amigo de Richard Wagner. Seguramente fue eso lo que más le sorprendió de un cónsul atípico ${ }^{20}$.

\footnotetext{
${ }^{14}$ Fétis, Pougin, 1881: 435.

15 Guimet, 1858.

16 Véanse las críticas aparecidas en Le Ménestrel (25-IX-1855, 27-XII-1857, 28-III-1858, 20-V-1860, 16-XII1860).

17 El Círculo Alemán, Club Germania, se reunía en el primer piso del Café Suizo, en la Plaza Real.

18 Humperdinck, Humperdinck, Mota, 2006: 10-18.

19 Humperdinck, Humperdinck, Mota, 2006: 8. Carta del 19 de noviembre de 1885.

${ }^{20}$ Humperdinck, Humperdinck, Mota, 2006: 2. Carta del 5 de junio de 1883.
} 


\section{El Museo Japonés}

Richard Lindau llegó a Japón hacia 1866, justo durante los años en que el país cambiaba el destino de su historia con el restablecimiento del poder imperial. Este cambio de rumbo supuso una auténtica revolución para todo el país que, desde entonces, inició una trepidante trayectoria de modernización y occidentalización. Todo el pueblo, todas las estructuras administrativas, toda la sociedad japonesa se vio afectada por unas profundas transformaciones. Y Richard Lindau estuvo en el lugar y momento oportunos para adquirir una excepcional colección de piezas artísticas; una variada colección de objetos y obras de arte japonés procedentes, en parte, de varios templos del país.

Durante el bakumatsu, y especialmente en los años de transición entre el régimen feudal y el nuevo sistema imperial, es decir, entre 1867 y 1868, el país vio surgir un movimiento nacionalista, conocido como haibutsu kishaku, decidido a restaurar el papel preponderante de la religión sintoísta en detrimento del budismo que, junto con el neoconfucionismo, había sido uno de los pilares de la política del antiguo régimen Tokugawa que finalmente salía del poder. Fruto de este fervor antibudista, muchos templos fueron destruidos y sus tierras fueron confiscadas; textos, libros e imágenes desaparecieron y los antiguos tesoros se diseminaron mientras que los monjes fueron forzados a volver a la vida secular. Fue una destrucción de grandes proporciones que implicó la pérdida de obras artísticas de alto valor, bronces, pinturas, caligrafías, templos y grandes estructuras arquitectónicas. Fue así que hacia 1868 muchas obras fueron destruidas o vendidas a particulares llegando a manos de personas como Richard Lindau.

Según explicaba el cónsul Lindau en Barcelona, su colección de arte nipón fue adquirida en Edo aprovechando la venta en subasta pública de varios objetos procedentes de templos budistas del país una vez finalizada la restauración Meiji, fruto del movimiento haibutsu kishaku. Parece que Richard Lindau, una vez más, siguió los pasos de su hermano Rudolph, quien unos años antes había adquirido su propia colección de arte japonés, un rico conjunto de piezas que de vuelta a Europa ingresó en un museo suizo ${ }^{21}$. En el caso de Richard Lindau, la adquisición alcanzó la elevadísima suma de medio millón de pesetas, es decir, para que nos hagamos una idea, el triple del valor total de las piezas que Japón presentó veinte años más tarde en la Exposición Universal de $1888^{22}$. Una vez las piezas estuvieron en su posesión, las clasificó, las evaluó y repartió algunas de ellas entre sus compañeros; el resto, aquellas que más apreciaba y de mayor valor, las retuvo para sí constituyendo el núcleo principal del Museo de Objetos Japoneses de Barcelona ${ }^{23}$.

Lindau expuso la colección en la sede del consulado de Alemania, inicialmente en el primer piso del número 90 del paseo de Gracia, trasladado posteriormente, hacia finales de la década de 1880, al entresuelo de la calle Pau Claris número 17. En el momento de distribuir las piezas a modo de exposición, puso una atención especial en preparar y organizar la extensa colección

${ }^{21}$ La colección de Rudolph Lindau ha sido recientemente localizada y está siendo estudiada por el Dr. Philippe Dallais, a quien agradezco la información proporcionada.

${ }^{22}$ Clapés, 1881: 91.

${ }^{23}$ Utilizamos el término "museo" con la voluntad de respetar la terminología establecida por la ICOM y, a su vez, mantener el término que se utilizó en Barcelona. Los salones donde se exponía la colección de artesanías y de arte japonés fue siempre descrita como Museo por todos quienes la visitaron; a pesar de ser una colección privada, esta estaba abierta a cualquier ciudadano interesado en el arte japonés, y así se anunciaba en periódicos, revistas y guías. Véase, a modo de ejemplo, una de las primeras noticias, que tenemos del "Museu del senyor Lindau" aparecidas en el Diari Català en febrero de 1881: ... ha pogut formarse un Museu com pochs n'hi hagi en Europa... podem assegurar que'l Museu del senyor Lindau es dels mes notables... és un Museu y no un Ateneo lo que avuy visitarà la Associació d'excursions catalana en casa del senyor Lindau, consul general d'Alemanya. Diari Català, 27-II-1881: 460. Diari Català, 28-II-1881: 470. 
artística japonesa con el fin de que pudiera ser apreciada en conjunto e individualmente, obra a obra. Con esta voluntad, encargó la construcción de vitrinas y mobiliario específico que dispuso en unos salones decorados según los parámetros de lo que en la Barcelona de la época se definía como estilo japonés, un estilo similar tal vez a la decoración interior de la Casa Cuadros de la Rambla, el Palacio Simon de la calle Mallorca o bien la Casa Coll y Pujol de Badalona. Las piezas, algunas en vitrinas y otras dispuestas como elementos decorativos, quedaron todas ellas integradas en armonía en las distintas dependencias de la sede del consulado. Humperdinck la describió el verano de 1883 como una lujosa casa decorada en estilo japonés ${ }^{24}$. Una casa lujosa situada en la avenida más prestigiosa de la ciudad burguesa y decorada según los gustos de la moda predominante entre la burguesía y la clase media de Barcelona: la moda del Japonismo.

El gusto por todo aquello que procedía de Japón había empezado a introducirse en Barcelona a inicios de la década de 1870. No sabemos si fue coincidiendo con su llegada, en 1876, o un poco más tarde cuando Lindau dispuso toda su colección de forma vistosa en la sede del consulado pero, en cualquier caso, creemos que sucedió alrededor del cambio de década, coincidiendo con el creciente interés por Japón. Muestra del oportunismo de Lindau es la construcción a principios del año 1881 del Pabellón Imperial Japonés, un edificio efímero situado en el centro de la ciudad que reproducía la arquitectura japonesa para mostrar en su interior la colección que Carles Maristany había adquirido recientemente durante una larga estancia en el archipiélago japonés ${ }^{25}$. El interés de la ciudad por el arte nipón fue lo que decidió a Lindau a ofrecer su colección única y excepcional:

MUSEO DE OBJETOS JAPONESES de Her Richard Lindau. Cónsul general de Alemania, paseo de Gracia 90, 1. ${ }^{\circ}$

Contiene esta colección un número considerable de curiosos objetos antiguos y modernos, notables por su mérito artístico y su valor intrínseco, colocados vistosamente en las distintas habitaciones del Consulado. Proceden de diversos templos y el Sr. Lindau, cónsul de Alemania en Yeddo, en 1868, los adquirió en pública licitación, después de haber sofocado el Mikado la rebelión de Taikun. Esta colección es una de las más completas que existen en Europa ${ }^{26}$.

Así es como se anunció en la sección de museos en las guías de la ciudad a partir de 1884 . Sin embargo, la primera visita al Museo de un grupo organizado, la hemos podido documentar tres años antes. Se trata de la visita que hicieron el 27 de febrero de 1881 quince miembros de la Associació d'Excursions Catalana, una sociedad creada en 1878 como escisión de la Associació Catalanista d'Excursions Científiques (1876) con la voluntad de difundir el patrimonio material e inmaterial de los pueblos de Cataluña. A esa visita se apuntaron quince socios, entre los cuales el abogado Valentí Almirall (1841-1904), padre del catalanismo político, y el comerciante Pere Clapés, socio fundador de la casa El Imperio Japonés (1892) instalada en Yokohama en $1894^{27}$. Todos ellos fueron recibidos por el cónsul, que les acompañó y les guió explicando su colección durante unas tres horas. Al día siguiente, uno de los asistentes a la visita publicó en el Diari Català:

El senyor Lindau, seguint les seves aficions o be complint encárrecs oficials que li han estat encarregats, ha dut a terme llargs $i$ notables viatges, havent viscut molts anys a

\footnotetext{
${ }^{24}$ Humperdinck, Humperdinck, Mota, 2006: 12. Carta del día 5 de junio de 1883.

${ }_{25}$ Bru, 2011: 270-275, 373-385.

${ }^{26}$ Roca, 1884: 212. Escudé, 1888: 74.

${ }^{27}$ No fueron ni el joven arquitecto Antoni Gaudí, recién ingresado en la Sociedad, ni tampoco los arquitectos Josep Vilaseca y Lluís Domènech i Montaner, socios interesados en la cultura japonesa. Bru, 2009-2010: 270.
} 
l'imperi japonès. Era allà quan les últimes revolucions han fet entrar a aquella nació asiàtica a la vida europea, i per tal motiu ha pogut crear un museu com pocs n'hi ha a Europa.

El senyor Lindau te tota la casa plena d'exemplars riquissims, alguns d'ells molt raros $y$ de gran valor. Objectes artistichs de marfil, mamparas, areas, bronzes com no's fan a Paris, lacas y brodats en or y colors, antichs y moderns cloisonnés, o sigui gerros y altres útils de metall adornats per un procediment especial, vestits, armadures, joies, albums, mobles, etc., etc., es veuen alli repartits per totes les sales, a les quals donen un aspecte inexplicable (...)

Nosaltres, que vam tenir el gust d'assistir com excursionistas a la visita, podem assegurar que el Museu del senyor Lindau es dels mes notables y que d'ell i de l'amabilitat del seu propietari en conservarem agradabilissim record ${ }^{28}$.

Afortunadamente, Pere Clapés Trabal, miembro de la Asociación y futuro impulsor del comercio de arte japonés en Barcelona, narró con mayor detalle esa visita en el boletín de la Asociación. Gracias a las descripciones de Clapés, podemos conocer cómo era y cómo se mostró la colección durante esos primeros años ${ }^{29}$.

\section{Una visita al Museo Japonés: las piezas de la colección}

La colección estuvo situada durante los primeros años en el piso noble del edificio numero 90 del paseo de Gracia. Al acceder al recibidor de la casa, ya decorado como el resto de salas con motivos japoneses, había varias pinturas y dos ricos biombos con paisajes detalladamente pintados con un grupo de patos y con dos armaduras samurai. Vistas estas pinturas, uno de los primeros objetos que llamaba la atención del visitante, tanto por su emplazamiento como por sus dimensiones, era una gran escultura de madera de Hotei, una talla que fue reproducida al cabo de unos años en varias publicaciones. Hotei, dios sintoísta de la felicidad, aparecía representado calvo, con sus largas orejas, sentado en el suelo con los pies entrecruzados, con su característico vientre prominente y con su eterna feliz sonrisa. Esta divinidad aparecía en otras esculturas menores, una de ellas de tamaño microscópico que Lindau veneraba: se trataba de una imagen trabajada con gran detalle a partir de un único grano de arroz.

La colección de esculturas incluía otras imágenes budistas, especialmente una destacada talla de madera lacada y dorada del buda Amida Nyorai (fig. 1), de época Edo, y una gran diversidad de okimono y de netsuke de marfil, algunos de ellos mostrados dentro de un mueble artísticamente esculpido con una recargada decoración probablemente de inicios de la era Meiji (fig. 2).

Había okimono y netsuke muy variados representando temas populares y fantásticos: dos ciegos peleándose, una reunión de monos, guerreros (fig. 3), una mujer jugando con su hijo, un esqueleto con un abanico bailando con una geisha, la personificación de la muerte y otras escenas extravagantes. La mayoría de ellos eran de finales del periodo Edo, algunos muy similares a los que coleccionó Eugène $\operatorname{Sarlin}^{30}$. La colección incluía también una ánfora de marfil decorada con

\footnotetext{
28 Diari Català, núm. 563, 28-II-1881: 470.

${ }^{29}$ Clapés, 1881: 87-92. Véase también descripciones posteriores de Antonio García Llansó (1891a, 1891b, 1891c, 1893).

${ }^{30}$ Importante Collection d'Ivoires de la Chine et du Japon. Collection Eugène Sarlin (première vente), Hôtel Drouot, 5/9-XI-1923, París, 1923: 131. Importante Collection d'Ivoires de la Chine et du Japon. Collection Eugène Sarlin (deuxième vente), Hôtel Drouot, 19/21-IV-1924, París, 1924; 20/28, fig. 223/351.
} 


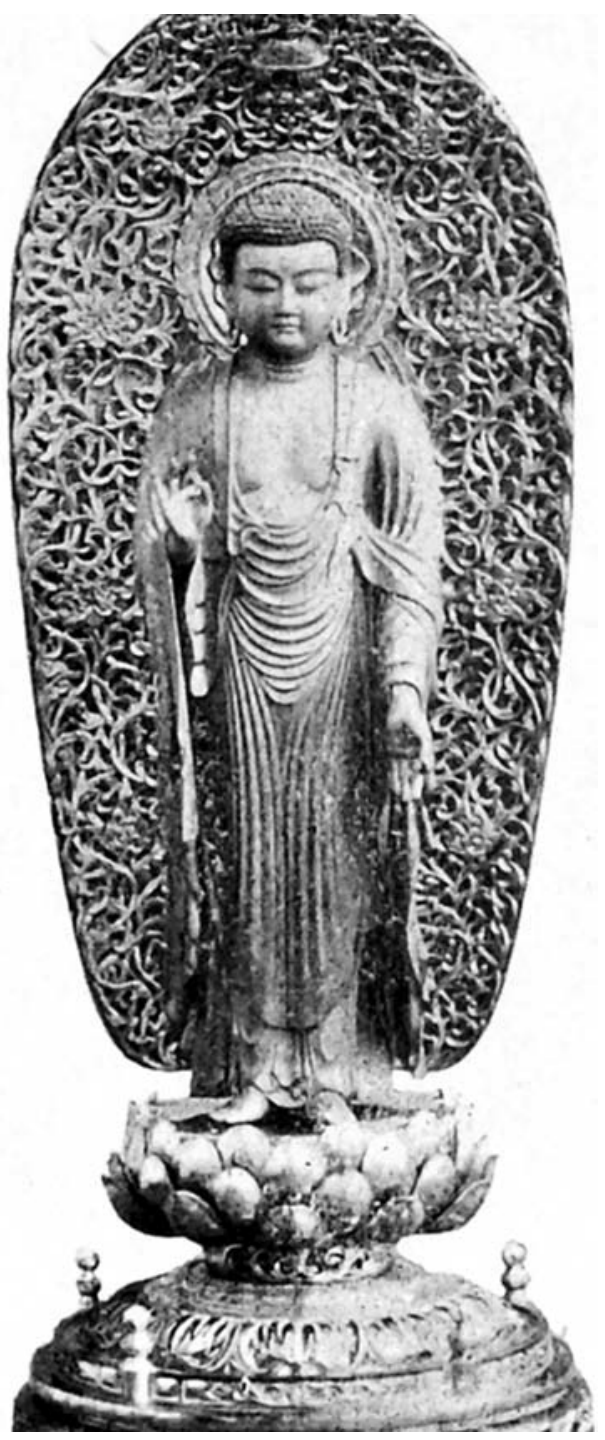

Fig. 1. Talla de madera dorada y lacada de Amida Nyorai (Edo) de la antigua colección de Richard Lindau.

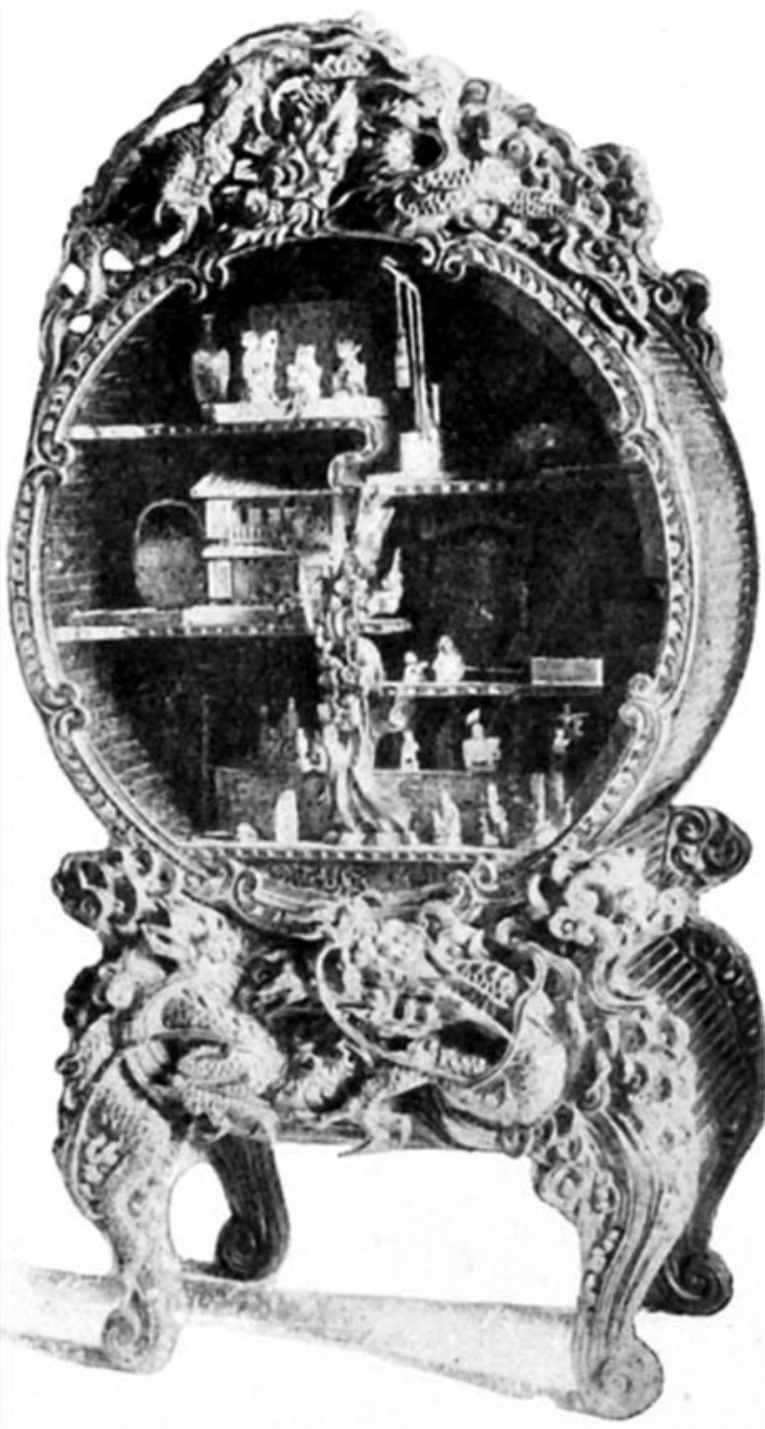

Fig. 2. Mueble con netsuke, okimono y otras piezas de la antigua colección de Richard Lindau.

la escena de un guerrero samurai dando muerte a un dragón, fechable de mediados siglo XIX, así como un okimono de proporciones considerables representando Jurôjin, uno de los siete dioses sintoístas shichifukujin que, juntamente con Hotei, eran considerados como dioses de la buena fortuna.

En el primer salón, cerca de una monumental chimenea, lucían dos grandes pebeteros (kôro), y varios bronces y jarrones decorados con motivos animales y vegetales. De las paredes colgaban algunas pinturas y algunos platos de bronce, entre los cuales destacaba uno que representaba un pájaro volando bajo la luz de la luna, con incrustaciones de oro y rodeado de 


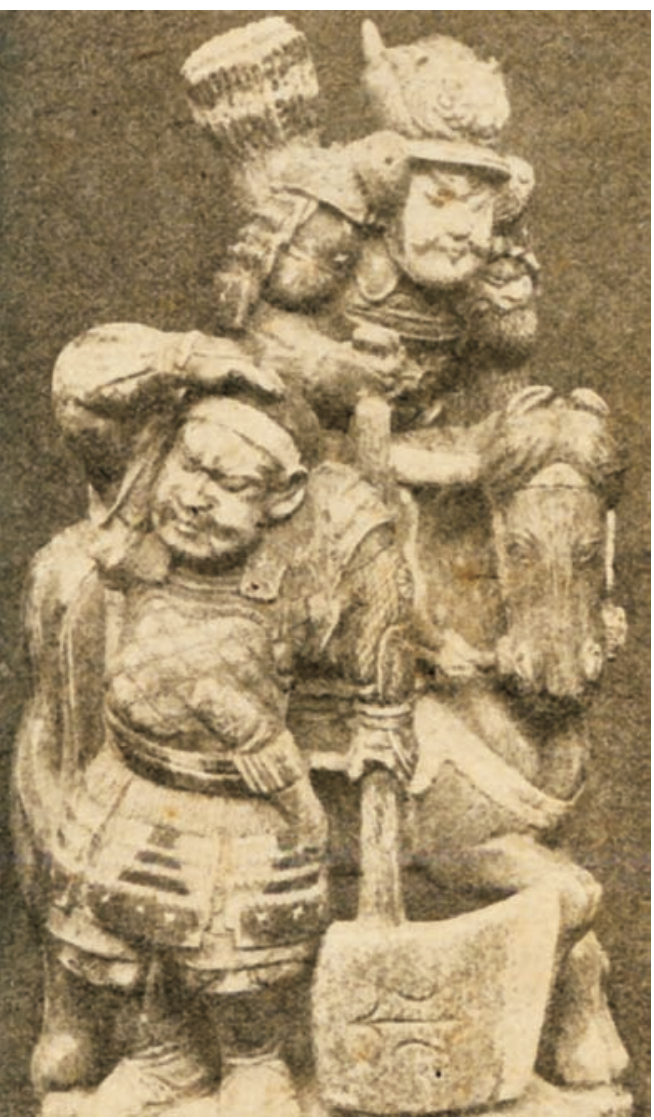

Fig. 3. Okimono de la antigua colección de Richard Lindau.

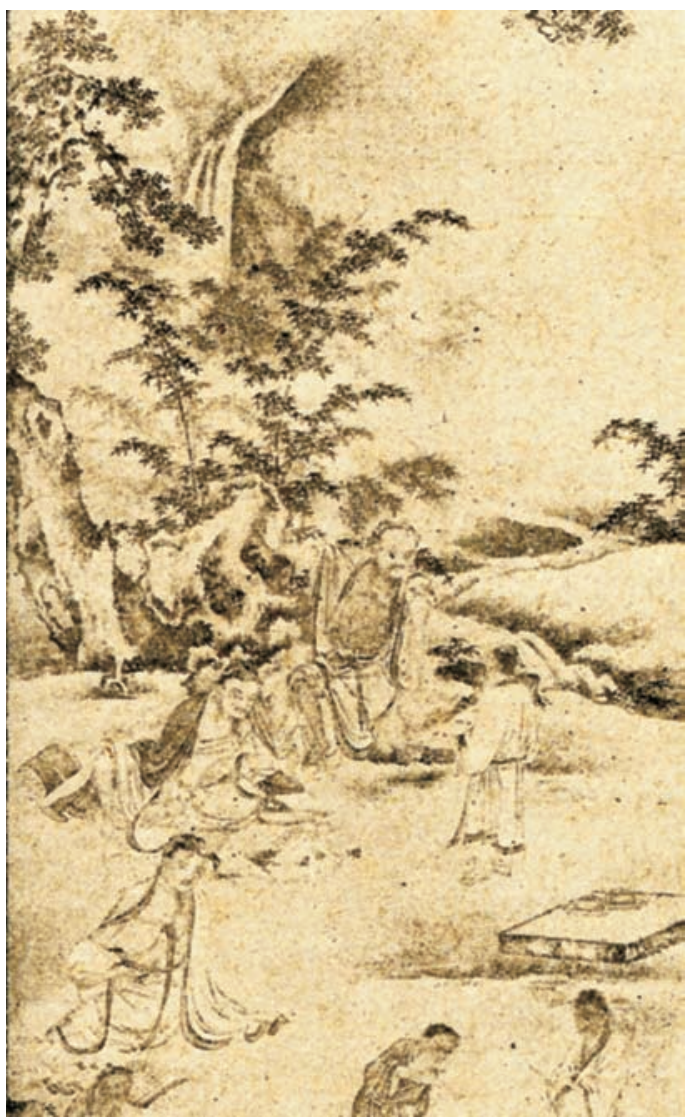

Fig. 4. Kakejiku de la antigua colección de Richard Lindau.

dragones fantásticos. Añadían las descripciones: por medio de hábiles é ingeniosas maceraciones los japoneses dan al cobre distintos colores y vanos tonos, figurando de todos ellos preciosos tipos en la colección del señor Lindau, ya negros y rojos, amarillos y verdes, bronces obscuros ó negro azulados según hayan sido los resultados que se propuso obtener el artifice $^{31}$.

La colección de Lindau también contaba con una gran variedad de ejemplares de indumentaria, tapices y tejidos bordados de seda y oro de época Edo expuestos unos dentro de vitrinas y otros, los vestidos, mediante maniquís. Acompañando estas piezas, las paredes de los distintos salones estaban recubiertas con kakejiku (fig. 4), pinturas y bordados con escenas muy variadas: desde la representación de paisajes y flores hasta escenas budistas del purgatorio y de la salvación. Sin embargo, destacaban los bordados de temática religiosa descritos con los siguientes términos: la llegada de Buddha a Corea; ratas blancas que se relacionan con el Ser Supremo a través de un tambor ya que en Japón hay un templo dedicado al dios Kamakura donde estas se pueden ver ${ }^{32}$. Asimismo, entre esos bordados había otro de oro sobre seda que, según el crítico

31 García, 1893: 4.
32 Clapés, 1881: 89 


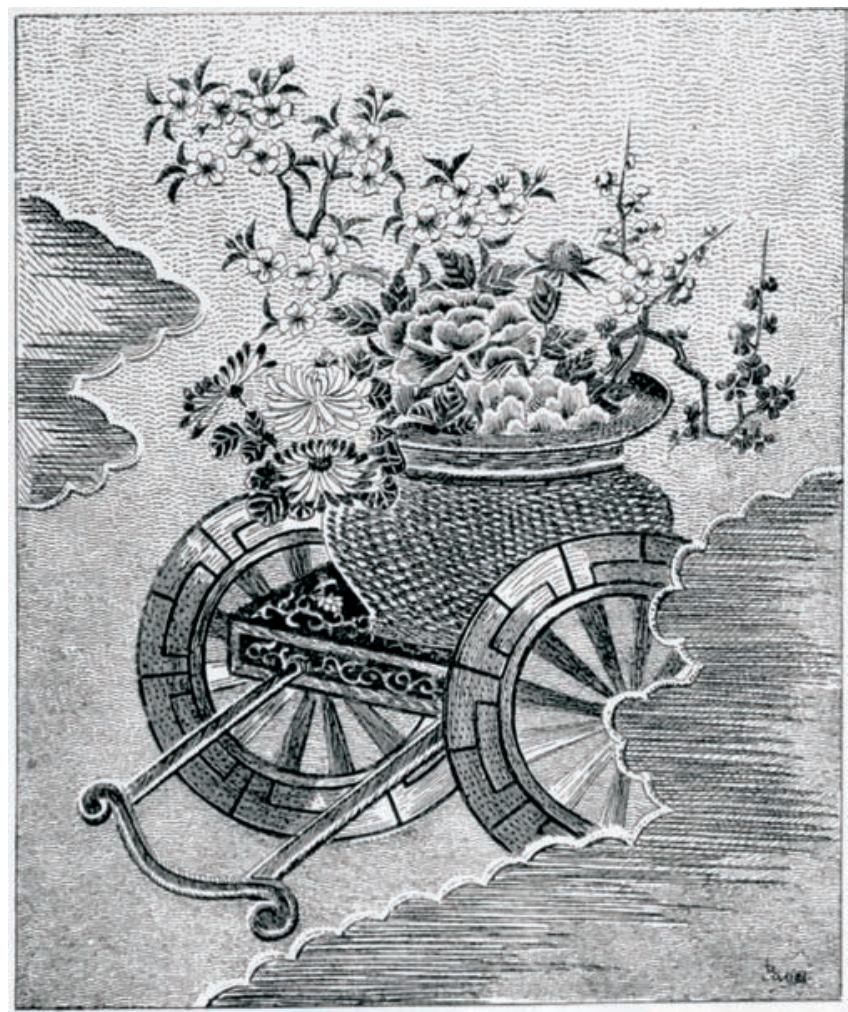

Fig. 5. Tapiz de oro bordado sobre seda (¿s. XVI?). Pieza de la antigua colección de Richard Lindau.

de arte Antonio García Llansó, procedía de un templo sintoísta y estaba firmado por un célebre

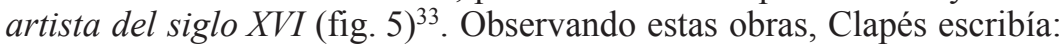

En cuanto se refiere a los bordados, son obra superiorísima. No recordamos haber visto nunca en este tipo de trabajo tan perfecto trazo de dibujo, tanta seguridad y tanta delicadeza, así como tampoco el gran conocimiento que ahí hay sobre la combinación de colores. Las cabezas de los personajes están tan bien realizadas que cuesta creer que sean pinturas hasta que uno está a punto de tocarlas ${ }^{34}$.

Una de las secciones más extensas de la colección era la de cerámicas y porcelanas. Había todo tipo de platos, jarras y jarrones, botellas de sake y utensilios que mostraban de forma didáctica la riqueza que caracterizaba el arte y la industria de la cerámica japonesa. García Llansó, que desde hacía algunos años había empezado a estudiar el arte japonés, explicaba como el cónsul Lindau adquirió esta colección en Japón en 1868 durante una incursión por el interior del país. García Llansó añadía: el señor Lindau, pudo saciar su curiosidad, dar pasto á su espíritu, investigando, comparando y estudiando el modo de ser de aquel pueblo, siempre grande, ya que así se revela en todas las épocas, y reunir copioso caudal de antecedentes acerca de sus progresos artísticoindustriales. En ese viaje de exploración, que llenaba un doble deseo, el que le imponía la repre-

\footnotetext{
33 García, 1891c: 420.

${ }^{34}$ Clapés, 1881: 90.
} 


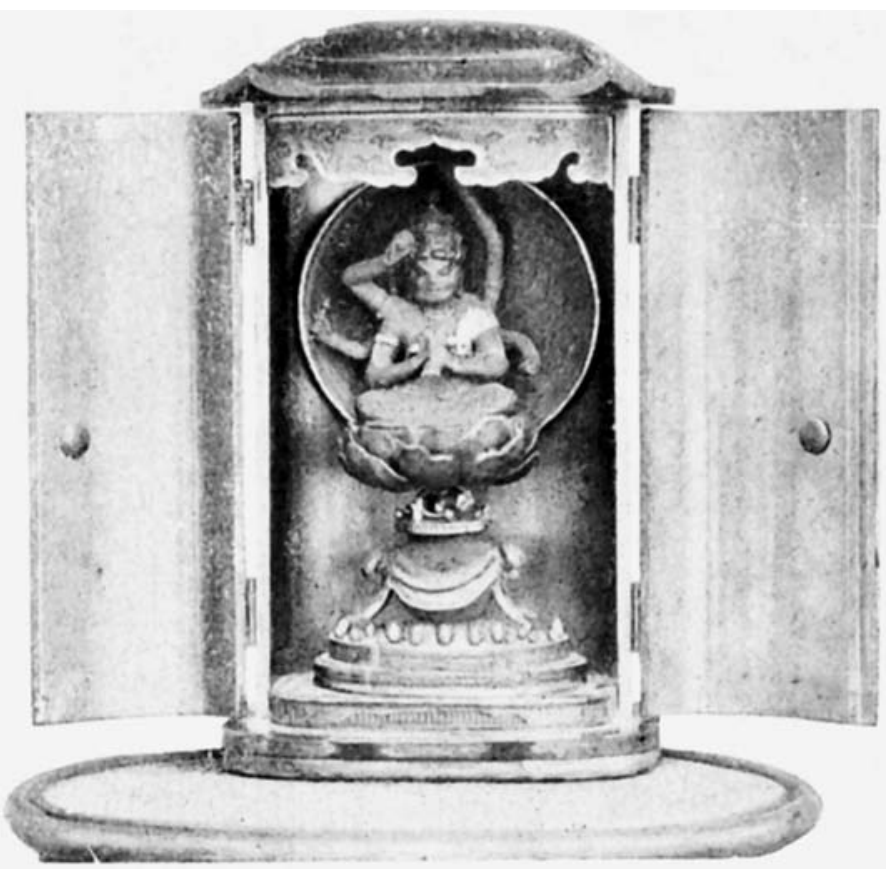

Fig. 6. Capilla zushi con la imagen de Aizen Myôô. Pieza de la antigua colección de Richard Lindau. sentación de su país y el de sus naturales inclinaciones, halló medio de adquirir objetos y piezas hasta el punto de que hoy continúan distinguiéndose las mismas variedades ${ }^{35}$. Según afirmaba García Llansó, el cual conocía perfectamente a Lindau, no todas las piezas fueron adquiridas en una subasta de Edo, sino que algunas de ellas procedían de otras compras realizadas en el mismo país. En este sentido, es posible que algunas de ellas hubieran sido compradas durante sus dos años de residencia en Nagasaki, en la isla de Kyûshû, bien conocida por sus hornos de cerámica. Así pues, la colección de cerámicas contaba con piezas de estilo Satsuma, de tonalidades doradas, cerámicas de Kyôto, de color rojo y dorado, de Imari (Arita), con sus características tonalidades azul y blanca, de Seto, de Kutani, de Yokohama y de Tokio, decoradas todas ellas con motivos y temáticas muy distintas; escenas guerreras y costumbristas, animales mitológicos, paisajes, etcétera.

La rica colección de lacas urushi, la constituían pequeños santuarios, bandejas, cajas y "guardajoyas". Entre las piezas budistas, sobresalían dos pequeñas capillas zushi de madera lacada de mediados de la época Edo; una de ellas representaba a Aizen Myôô (fig. 6). Muchas otras piezas lacadas estaban decoradas con motivos vegetales y de flores y pájaros, ramajes con fondos dorados mediante la técnica maki-e, así como acompañados de incrustaciones de nácar. Curiosamente, para profundizar en el conocimiento del arte de este tipo de piezas de laca, Pere Clapés recomendaba la lectura del libro de Josep Jordana La agricultura, la industria y las bellas artes en el Japón (1879), el cual era en aquellas fechas aun el único publicado en España en el que se hablaba de arte japonés (fig. 7). Asimismo, los visitantes podían ver una serie de muebles y objetos de madera y de metal, cajas, biombos y mesas decoradas con técnicas y materiales diversos, con urushi, con incrustaciones y con variadas aplicaciones metálicas. Entre ellas, era especialmente interesante una mesa de bambú y los jarrones y platos de esmalte cloisonné.

También llamaba la atención una barca artísticamente trabajada en una caña de bambú, un reposacabezas hako-makura procedente de una casa de cortesanas, instrumentos musicales, varias fotografías, algunas alfombras, un gran Buda de bronce, así como dos cigüeñas (fig. 8), armas y armaduras (fig. 9) y varios candelabros, también de bronce. Finalmente, destacaba una extensa colección de los populares grabados xilográficos de la escuela ukiyo-e entre los que sobresalía, sorprendentemente, la exposición de estampas eróticas shunga y otras obras de los

\footnotetext{
35 García, 1893: 4.
} 
principales artistas de los siglos XVIII y XIX:

En donde se revela el sentimiento artístico de los japoneses es en la colección de grabados y dibujos, tan interesantísima, que no dudamos en llamar acerca de ella la atención de nuestros artistas. Allí demuestran su valía los compañeros de Hokusai, su indiscutible maestría en acusar una forma por medio de un sencillo trazo, siempre elegante, preciso y con conocimiento exacto del natural, campesinos, guerreros, tipos diversos, animales, plantas y cuadros de costumbres o eminentemente picarescos, cual no los han podido concebir los artistas europeos, que rebasan el limite que existe entre lo sencillamente picaresco y lo grosero, entre lo que se adivina y lo que se ve, entre lo que acusa un humorismo ingenioso y la vulgar pornografia ${ }^{36}$.

Trasladado a la nueva sede del Consulado General de Alemania, en la calle Pau Claris, el Museo se mantuvo abierto durante unos veinte años. En 1893, García Llansó hacía un llamamiento a artistas e industriales para que fueran a conocer una colección, la de Richard Lindau, que podía convertirse en una fuente continua de inspiración y de estudio:

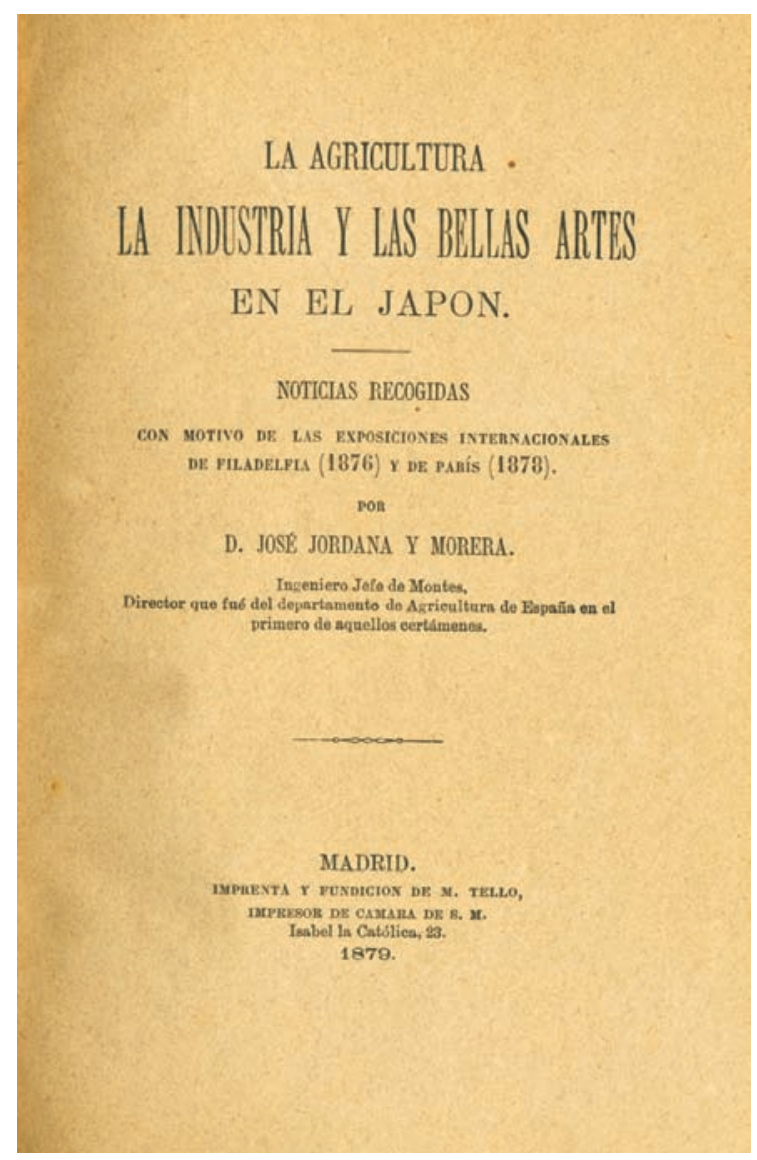

Fig. 7. Portada del libro La agricultura, la industria y las bellas artes en el Japón (1879) de José Jordana. Primer libro sobre arte y artesanías japonesas publicado en España.

La colección japonesa del señor Lindau, única en España, cuya formación sería hoy poco menos que imposible, digna de formar parte de un Museo oficial, pues á nadie podrá ocultarse su importancia y cuán provechoso sería su examen para nuestros artistas é industriales, puesto que de ella podrían obtener provechosas enseñanzas, ya que emanarían de las creaciones de un pueblo que figura el primero por el sentimiento artístico y por su dominio industrial ${ }^{37}$.

El llamamiento, similar al que se hizo al inaugurarse el Pabellón Imperial Japonés de 1881 y al que realizó desde la Academia de Ciencias y Artes de Barcelona José Masriera en 1884, fue escuchado porque ya en aquellas fechas el arte japonés era tomado en consideración como mo-

\footnotetext{
36 Ibidem.

37 Ibidem.
} 


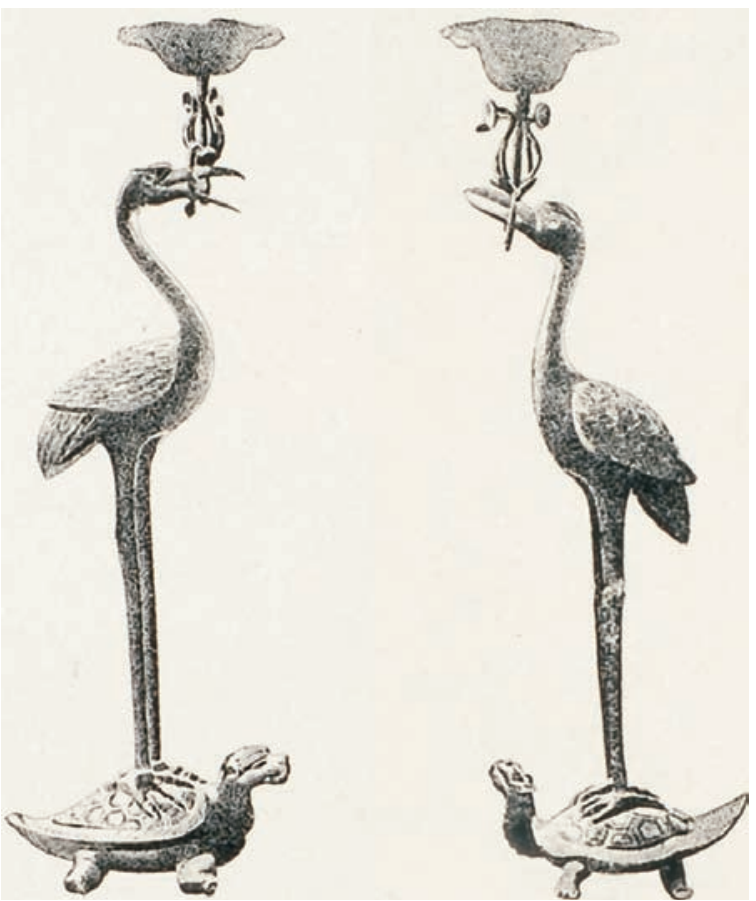

Fig. 8. Cigüeñas de bronce de la antigua colección de Richard Lindau.

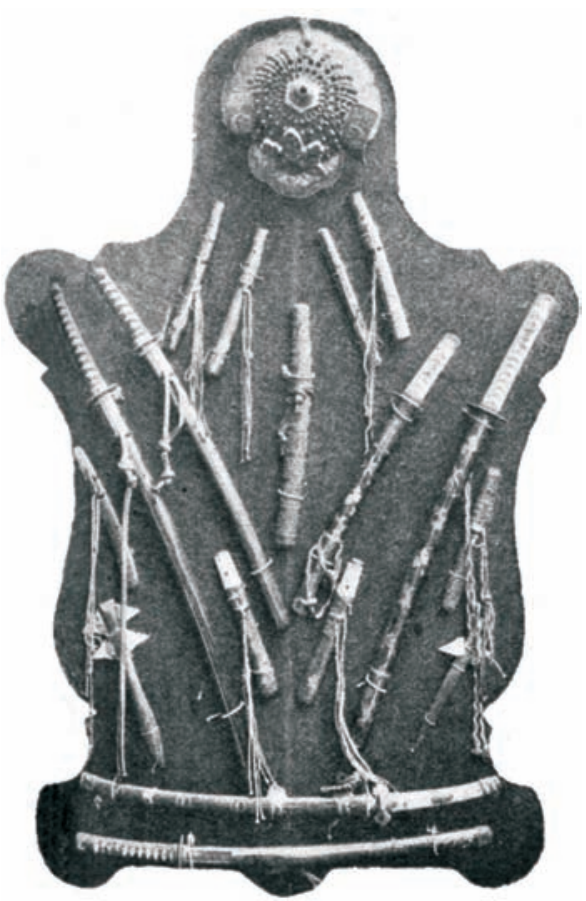

Fig. 9. Conjunto de armas samurai de la antigua colección de Richard Lindau.

delo para muchos artistas e industriales de la ciudad. En 1898 el Museo seguía anunciándose en las guías de Barcelona como Museo de objetos japoneses de Herr Richard Lindau. Sin embargo, dos años más tarde, en 1900, con Lindau a punto de dejar el cargo, el consulado se trasladó a una nueva sede y de esta colección ya nunca se supo nada más ${ }^{38}$.

\section{Apuntes para una valoración de la colección Lindau}

Actualmente aun desconocemos dónde se conservan las piezas de la colección de Richard Lindau ${ }^{39}$. Por este motivo, las valoraciones que podemos hacer de la colección Lindau son parciales y parten únicamente de las descripciones y reproducciones de época. En este sentido, solo

38 En mayo de 1900 el consulado se trasladó al primer piso del edificio núm. 406 de la calle Diputación.

39 Las hemos buscado en museos y colecciones de España y del extranjero, también en el Museo creado por Emile Guimet, quien tan elogiosas palabras dedicó al cónsul Lindau durante su juventud. Los museos públicos de Barcelona no conservan ninguna de sus piezas. Tampoco las hemos podido localizar en otras colecciones españolas. Las consultas realizadas a la Dra. Hélène Bayou, conservadora de la colección japonesa del Musée Guimet de París, así como al Dr. Alexander Hofmann, conservador del Museum für Ostasiatische Kunst de Berlín, al Dr. Stephan Graf von der Schulenburg, conservador del Museum für Angewandte Kunst de Frankfurt, y a la Dra. Bettina Clever, conservadora del Museum für Ostasiatische Kunst de Colonia, a quienes agradecemos su ayuda y colaboración, resultaron infructuosas. Inicialmente pensábamos que tal colección podría haber sido comprada por Josep Mansana hacia 1900, pero ninguna de sus piezas coinciden con las descritas por quienes visitaron el Museo de Richard Lindau. 
conocemos las imágenes, fotografías y grabados que se publicaron entre 1891 y 1918 en Barcelona, en varios artículos de La Ilustración Hispano-Americana (1891) y La Vanguardia (1893) y en las monografías Dai Nipon (1905), El Japón a la vista (1905) y Manual de Arte Decorativo (1918), las cuales sirvieron, a su vez, para la ilustración puntual de otros libros como La raza amarilla (1898) de Alfredo Opisso y Cuentos orientales (1908) de Magdalena de Santiago Fuentes.

En primer lugar, si observamos el listado de piezas que fueron expuestas durante la década de 1880, es factible pensar que la colección no fue fruto de una sola adquisición en Edo en 1868. Ya hemos visto cómo García Llansó indicaba que algunas de las cerámicas habían sido compradas en el interior del país. En este sentido, podemos creer que la colección fue creciendo progresivamente a partir de compras posteriores, algunas de ellas tal vez adquiridas durante la Exposición Universal de Barcelona de 1888. Así lo creemos porque en la colección había varias fotografías, inusuales en el Japón de los años 60, así como muebles de época Meiji. En esta misma dirección podría apuntar la enumeración que García Llansó hacía de cerámicas de estilo Satsuma, popularizadas en época Meiji a partir de la Exposición Universal de París de 1867, y sobre todo por la presencia de cerámicas de Yokohama, ciudad portuaria que no empezó a desarrollar la industria cerámica hasta la llegada de Miyagawa Makuzu Kozan en 1870, artista que participó en la Exposición Universal de $1888^{40}$.

A falta de imágenes que nos permitan ver lo que se describió como una rica y fascinante colección de grabados, pinturas y tapices, otras piezas muy interesantes eran las de esmalte cloisonné. A partir de los grabados y las fotografías publicadas, podemos certificar la presencia de como mínimo ocho piezas: dos platos, un par de jarrones para té (chatsubo) y dos pares de vasos para flores (hanaike). Si nos fijamos en sus tipologías y motivos decorativos, podremos comprobar cómo esos ejemplares eran muy similares a las piezas que coleccionó en Liverpool James L. Bowes (fig. 10) ${ }^{41}$. Tanto las tipologías, todas ellas tradicionales, como los motivos ornamentales, las imágenes de los dragones, las carpas o el ave fénix, eran el fruto del arte de un mismo periodo y de unas prácticas artesanales similares. Y ahí es donde encontramos su especial interés ya que se trataba de unas piezas que a finales del siglo XIX suscitaron una viva polémica entre quienes las consideraban obras de los siglos XVII-XVIII y los que creían que fueron realizadas a mediados del siglo XIX, cuando se redescubrió la técnica del esmalte cloisonné.

La historiografía actual sitúa el origen de los esmaltes cloisonné japoneses en 1838, cuando el artista de Nagoya Kaji Tsunekichi, sin maestro previo, reinventó una técnica que había existido débilmente hacia el 1600 en torno a la familia Hirata ${ }^{42}$. Sin embargo, si retrocediéramos a inicios de la era Meiji, cuando Lindau adquirió y mostró sus piezas cloisonné, la opinión estaba dividida. Eso fue así a raíz de la publicación, en 1884, de una periodización de las obras de esmalte cloisonné propuesta por James L. Bowes. Bowes, en contacto con la familia Hirata y gran coleccionista de closionné, proponía tres etapas cronológicas con características estilísticas y tipológicas diferenciadas: Early (s.XVI-XVII), Middle Period (s.XVII-XIX) y Modern (s.XIXMeiji), siendo las obras de este último período producciones de la era Meiji pensadas en gran medida para la exportación ${ }^{43}$. Las piezas de su colección, adquiridas en Europa entre 1865 y 1874,

40 Hida, 1995: 70-96.

41 Bowes, 1886.

${ }^{42}$ El redescubrimiento de la técnica cloisonné permitió que entre 1865 y 1875 se desarrollara una nueva industria artística que tuvo sus años de mayor esplendor entre 1880 y 1900 con los artistas Namikawa Yasuyuki (1845-1927) y Namikawa Sôsuke (1847-1910), ambos presentes en la Exposición Universal de Barcelona (1888). Coben, Fester, 1982: 19-22. Impey, Fairely, 1994: 20. Irvine, 2006: 16-17.

${ }^{43}$ Del estudio de Bowes Japanese Enamels se hizo una primera edición privada en 1884 y una segunda en Londres en 1886. Bowes, 1895: 1. 


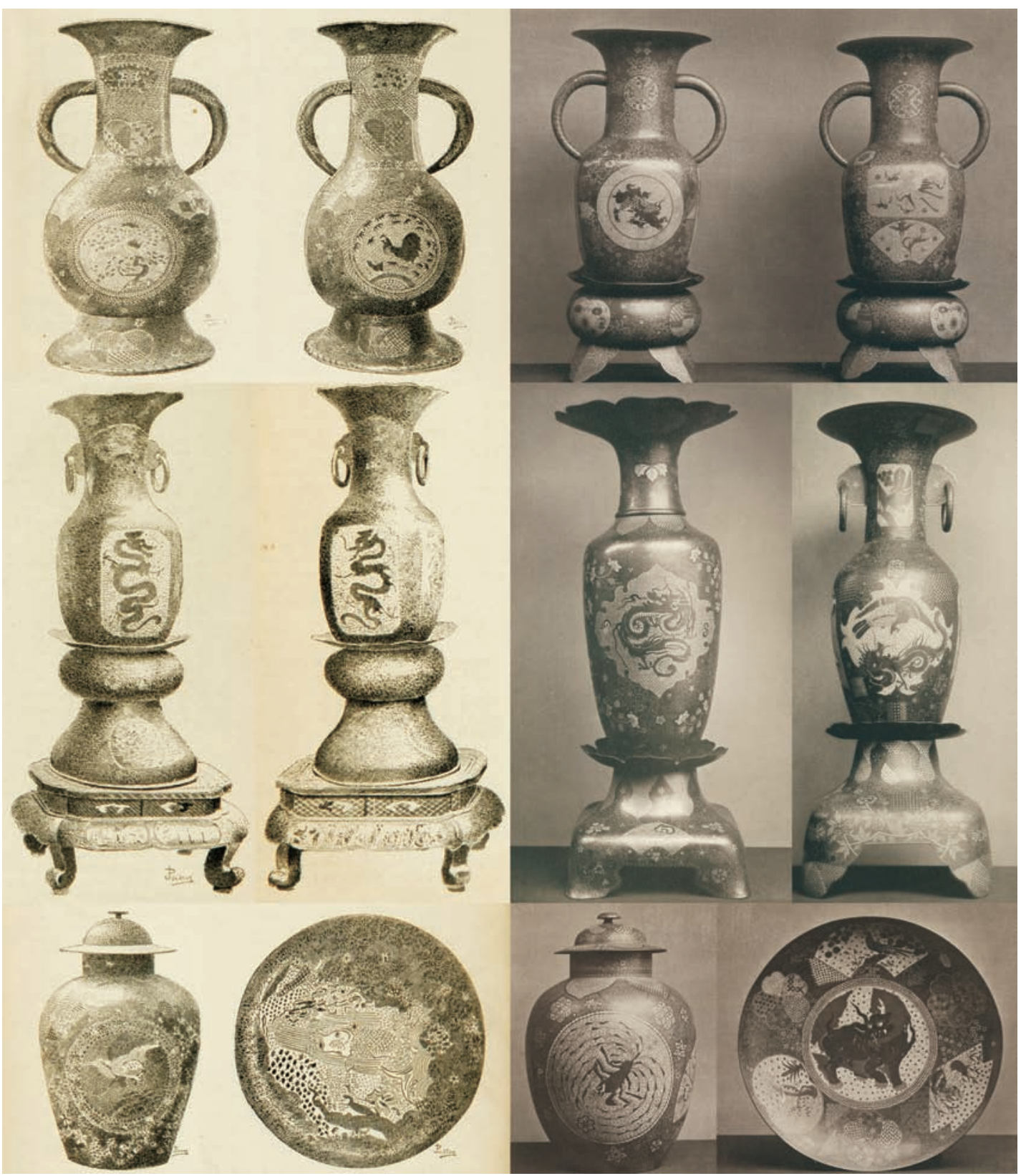

Fig. 10. Hanaike, chatsubo y platos de esmalte cloisonné. Piezas de las colecciones Lindau (izquierda) y Bowes (derecha). 
eran, según Bowes y George A. Audsley, obras de mediados de la era Tokugawa, probablemente de los siglos XVII y XVIII; periodo que, a falta de la aparición de los grandes maestros de la era Meiji, consideró como el más brillante de la historia del esmalte cloisonné japonés. No deja de ser interesante destacar que los ejemplares de Lindau, adquiridos en 1868, fuesen tan similares a los de Bowes y fuesen identificados por Lindau como piezas procedentes de antiguos templos sintoístas consideradas como importantísimas piezas así por lo artístico del trabajo como por el tamaño de algunas de ellas, pues hay dos ánforas que tienen unos 5 pies de altura, como también otras por la antigüedad que acusan, pues el señor Lindau nos destacó en la greca de una de ellas que, al construirse, aun no sabían trazar la línea recta ${ }^{44}$. Esta teoría surgida de los estudios de Bowes fue rebatida por el japonólogo irlandés Frank Brinkley. Según Brinkley, todas eran piezas posteriores a 1838, considerando que las piezas de la colección Bowes habían sido producidas por discípulos de Kaji Tsunekichi en Nagoya probablemente entre 1865 y $1878^{45}$.

Más allá de la controversia suscitada por los esmaltes, el ejemplo del Bowes Museum resulta interesante debido a su semejanza con el de Lindau, similar tanto en cuanto a fechas como en cuanto al tipo de piezas, a pesar de que la colección Lindau sigue siendo menos conocida ${ }^{46}$. Si bien Bowes no viajó a Japón y tuvo que adquirir las piezas en exposiciones, subastas y establecimientos de Europa y Estados Unidos, consiguió formar una colección privada de arte japonés de gran interés que, aunque se formó entre las décadas de 1860 y 1870, no abrió al público de manera oficial en Liverpool hasta el 19 de junio de $1890^{47}$.

\section{El Museo de Richard Lindau en su contexto}

A fin de valorar de manera justa el Museo de Richard Lindau es necesario conocer y tener en cuenta casos similares, anteriores y contemporáneos. Si hubiésemos de considerar los precedentes del Museo de Herr Lindau, deberíamos señalar en primer lugar y de forma destacada la figura de Philipp Franz von Siebold y el Japanese Museum abierto en Leiden en el año $1837^{48}$.

Siebold fue la excepción en una Europa donde las colecciones de arte oriental quedaron limitadas a los palacios de las monarquías, algunas casas nobles, puntuales monasterios y muy pocos museos. Los primeros ejemplos los encontramos en el norte de Europa, en las colecciones del Ashmolean Museum de Oxford, abierto en 1683, en el Japanisches Palais, actual sede del Museo de Etnología de Dresde, palacio decorado en 1727 con motivos orientales para albergar colección de porcelanas niponas del rey Augusto II, o bien en el Royal Cabinet of Rarities (Koninklijk Kabinet van Zeldzaamheden) de La Haya, abierto en 1816 y donde ingresaron las colecciones de Jan Cock Blomhoff y Johannes F. Van Overmeer Fisscher ${ }^{49}$. Otras grandes instituciones públicas que adquirieron durante el siglo XIX algunas piezas de arte japonés fueron el Musée de la Marine de París, la Bibliothèque nationale de France, el South Kensington Museum de Londres, el British Museum, o el Rijksmuseum de Amsterdam ${ }^{50}$. Asimismo, las crecientes colecciones de estos mu-

44 Clapés, 1881: 89-90.

45 Coben, Fester, 1982: 24.

${ }^{46}$ Las piezas de la colección Bowes son mejor conocidas gracias a los libros ilustrados que el mismo propietario publicó, gracias a la guía del museo aparecida en 1894, así como también gracias a la localización de algunas de sus piezas, conservadas en colecciones privadas y en museos ingleses a partir de la subasta realizada en Manchester en 1901, un año después de la muerte de Lindau. Baird, 2000: 133-135.

47 Sin embargo, las piezas de la colección Bowes habían sido expuestas anteriormente en varias exposiciones, como en la exposición de arte oriental celebrada en el Liverpool Art Club en 1872. Bowes, 1894.

48 Van Gulik, 1989a: 378-391.

49 Murray, 1840: 30-31. Van Gulik, 1989b: 75-81.

50 Johnson, 1982: 344. Floyd, 1986: 106. Kornicki, 2004: 21-38. Lacambre, 2009: 32-41. 
seos, fueron acompañadas por otras de iniciativa privada, a menudo efímeras pero que no debemos olvidar, como la colección oriental del conde Pier Alessandro Garda (1821), el Japansch Magazijn de La Haya (1828), la colección conocida como Musée Chinois et Japonais de Paul Ginier, de Marsella (c.1840-1842), el Musée Japonais et Chinois del coronel Dupin (1862), o bien el llamado Musée Oriental de París, una exposición dedicada a las artes del Oriente Próximo, Medio y Lejano Oriente presentada en otoño de 1869 en los salones de la Union Centrale des Beaux-Arts con la intención, según expresaba Philippe Burty, de convertirse en un auténtico Museo de Arte Oriental permanente para la capital francesa ${ }^{51}$. Destacaron especialmente el Musée Guimet de Lyon (1879), así como las colecciones del General Henry Pitt Rivers (1827-1900), mostradas en el Pitt-Rivers Museum de Oxford (1884), la de Vincenzo Ragusa en Palermo (1883), el Musée japonais proyectado como parte integrante del establecimento de arte japonés del comerciante Siegfried Bing, anunciado en el catálogo ilustrado del Salón de 1884, y la colección Merton Russell-Cotes, expuesta en la Japanese Drawing Room del Royal Bath Hotel de Bournemouth (c.1885). En cuanto a España, además del Museo Oriental (1874) creado por los padres agustinos en el Real Colegio Seminario de Valladolid, destacó de forma especial la colección adquirida en Japón por Tiburcio Rodríguez, primer Encargado de Negocios de España en Japón hasta 1873, la cual, expuesta en su residencia particular de Madrid, contaba con todo tipo de cerámicas y porcelanas, esmaltes cloisonné creados en Toshima por la Nagoya Cloisonné Company, lacas del periodo Edo, armas y armaduras, abanicos, pinturas y tapices.

Entre estos casos, uno que podría ser especialmente similar al de Richard Lindau fue el del escultor siciliano Ragusa. Vincenzo Ragusa, residente en Tokio como profesor de escultura en la Technical Fine Arts School entre 1876 y 1882, adquirió una extraordinaria colección japonesa de más de 4.000 piezas de bronce, cerámica, artes decorativas, estampas, objetos artísticos y objetos de uso cotidiano. De regreso a su ciudad natal, Palermo, hacia 1883 decidió adecuar su residencia, cerca de la plaza Ruggero Settimo, para convertirla en un Museo giapponese ${ }^{52}$. Como en el caso de Lindau, Ragusa expuso, repartidas en diez salones, muchas de las piezas de su extensa y variada colección. El museo proyectado por Ragusa, sin embargo, estuvo abierto durante muy pocos años ya que a partir de 1888 muchas de las piezas fueron vendidas al Museo Preistorico Etnografico "Luigi Pigorini" de Roma ${ }^{53}$.

Lindau, Guimet, Bing, Ragusa y Bowes, con iniciativas privadas para mostrar al público sus ricas colecciones de arte japonés, formaron parte de una extensa generación que hizo de puente entre el coleccionismo de Siebold y los primeros grandes museos de arte oriental de Inglaterra, Francia y Estados Unidos. Desde inicios de la década de 1860, fueron muchos quienes empezaron a comprar arte japonés en París para formar magníficas colecciones privadas, como las Edmond de Goncourt y Philippe Burty, visitadas y elogiadas por algunos de los principales pintores impresionistas. Y fueron muchos los que prestaron sus piezas para que fueran mostradas en exposiciones y certámenes durante los años 80 y 90 , pero pocos fueron los que ofrecieron y anunciaron sus colecciones japonesas de forma permanente a toda la población.

Enrico Cernuschi, junto con el crítico de arte Théodore Duret, inició en 1871 un viaje a Oriente, donde adquirió más de cinco mil obras de arte; colección que permitió abrir en 1898 el Musée Cernuschi. Un viaje similar es el que emprendió Émile Guimet en 1876, fruto del cual nació el Musée Guimet de Lyon y en 1889 el Musée d'Art Oriental de París, actual Musée nacional des Arts Asia-

\footnotetext{
51 Weisberg, 1993: 110-113.

52 Crisafulli, Paderni, Riotto, 2009. Véase tambien la publicación de Raguza aparecida en ocasión de la inauguración del museo (Per l'inaugurazione del museo giapponese a Palermo, 1883).

53 Crisafulli, Paderni, Riotto, 2009: 123-143, 321-326. Premoli, 1891: 18. Un caso parecido fue el de Edardo Chiossone (1833-1898), autor de una extensa colección durante su estancia en Japón que estableció las bases del museo que actualmente lleva su nombre en Génova.
} 
tiques. Ese mismo año, el coleccionista Edmond Michotte intentó abrir otro Musée japonais en Bruselas y Enrico di Borbone partió hacia Japón, donde adquirió muchas de las piezas del futuro Museo d'Arte Orientale Ca'Pesaro de Venecia. Todos ellos siguieron un camino similar al de Richard Lindau al abrir, hacia 1880, uno de los primeros museos de arte japonés del sur de Europa.

La colección de Richard Lindau, bien conocida por los aficionados al arte japonés de Barcelona, se ofreció al público de la ciudad coincidiendo con el pleno desarrollo del fenómeno del Japonismo en Cataluña y, por lo tanto, se convirtió en un punto de referencia para todos aquellos interesados en conocer y ver arte japonés sin tener que salir de la ciudad. Era una colección muy extensa y diversa, a la vez que relativamente similar a las que James L. Bowes y Vincenzo Ragusa mostraron en Liverpool y Palermo respectivamente. Sin embargo, así como estas últimas colecciones son conocidas, especialmente la de Ragusa, custodiada en el Museo Nazionale Etnografico Preistorico "Luigi Pigorini" de Roma, en el caso de Richard Lindau, sus piezas continúan sin ser localizadas. Persistiendo en la investigación que aquí presentamos, esperamos que en un futuro las piezas del Museo de Objetos Japoneses de Richard Lindau puedan llegar a ser localizadas y estudiadas, como las de su hermano Rudolph Lindau, para contribuir así a la recuperación de una página muy destacada de la historia del coleccionismo de arte oriental en España.

\section{BIBLIOGRAFÍA}

Archivo Diplomático y Consular de España, 16-VI-1888, "Movimiento del personal extranjero", p. 177.

Avitable, Gunhild, "Gottfried Wagener", The Nasser D. Khalili Collection of Japanese Art. Seleted Essays, vol. I, Londres, The Kibo Foundation, 1995, pp. 98-109.

Baird, Christina, "Japan and Liverpool. James Lord Bowes and his legacy", Journal of the History of Collections, vol. 12, núm. 1, Londres, 2000, pp. 133-135.

Bowes, James L., Japanese enamels, Londres, Bernard Quaritch, 1886.

Bowes, James L., Handbook to The Bowes Museum of Japanese Art Work, Liverpool, Streatlam Towers, 1894.

Bowes, James L., Notes on shippo. A sequel to Japanese enamels, Londres, Kegan Paul, Trench, Trübner \& Co, 1895.

Bru i Turull, Ricard, "Notes per a l'estudi del col-leccionisme d'art oriental a la Barcelona vuitcentista", Butlletí de la Reial Academia Catalana de Belles Arts de Sant Jordi, vol. XVIII, 2004, pp. 233-257.

Bru i Turull, Ricard, "Un Museu d'Art Japonès a la Barcelona de 1880", Serra d'Or, n. ${ }^{\circ}$ 545, mayo 2005, pp. 41-45.

Bru i Turull, Ricard, "El comerç d'art japonès a Barcelona (1887-1915)", Locus Amoenus, vol. 10, 20092010, pp. 259-277.

Bru i Turull, Ricard, Els orígens del Japonisme a Barcelona, Barcelona, Institut Món Juic, 2011.

Clapés Trabal, Pere, "Visita al Museo del Sr. Richard Lindau, Cónsul General de Alemania lo dia 27 de febrer de 1881", Butlletí Mensual de la Associació d'Excursions Catalana, n. ${ }^{\circ}$ 31, Barcelona, 1881, pp. 87-92.

Coben, Lawrence A., Fester, Dorothy C., Japanese Cloisonné. History, Technique and Appreciation, Tokio, 1982.

Crisafulli, Vincenzo; Paderni, Loretta; Riotto, Maurizzio, Kiyohara Tama. La collezione dipinta, Palermo, Sellerio, 2009.

Diari Català, 28-II-1881, "Lo Museu del senyor Lindau”, p. 470.

Escudé Bartolí, Manuel, "Industria", Órgano Oficial. La Exposición Universal de Barcelona, n. ${ }^{\circ}$ 57, Barcelona, 22 de agosto del 1888, p. 74.

Fétis, François-Josep; Pougin, Arthur, Biographie Universelle des Musiciens et Bibliographie Génerale de la Músique. Supplément et Complement, vol. I, Paris, Librairie de Firmin-Didot et Cie., 1881.

Floyd, Phylis, "Documentary evidence for the availability of Japanese imagery in Europe in nineteenth-century public collections", The Art Bulletin, vol. 68, n. ${ }^{\circ}$ 1, marzo de 1986, pp. 105-141.

García Llansó, Antonio, "Colección japonesa de D. Ricardo Lindau, cónsul de Alemania en Barcelona”, La Ilustración Hispano-Amercicana, 29-III-1891a, pp. 204-206. 
García Llansó, Antonio, "Barcelona: Colección japonesa de D. Ricardo Lindau", La Ilustración HispanoAmercicana, 3-V-1891b, pp. 285-286.

García Llansó, Antonio, "Barcelona: Colección japonesa de D. Ricardo Lindau", La Ilustración HispanoAmericana, 5-VII-1891c, pp. 420-421, 427.

García Llansó, Antonio, “Colección japonesa de Herr Richard Lindau”, La Vanguardia, 11-II-1893, p. 4.

García Llansó, Antonio, Dai Nipon, Barcelona, Soler, 1905.

Guimet, Emile, "Concert de Mm. Lubeck, Lindau et Pontet", Revue du Lyonnais. Recueil historique et littèraire, vol. XVI, Lyon-París, 1858, p. 173.

Hida, Toyojiro, "Exporters of Meiji decorative arts", The Nasser D. Khalili Collection of Japanese Art. Seleted Essays, vol. I, Londres, The Kibo Foundation, 1995, pp. 70-96.

Humperdinck, Wolfram; Humperdinck, Engelbert; Mota, Jordi, "Engelbert Humperdinck", Wagneriana Castellana, n. ${ }^{\circ}$ 59, 2006, pp. 10-18.

Impey, Oliver; Fairely, Malcolm, "Japanese Cloisonné Enamel”, Meiji no takara. Treasures of Imperial Japan. Enamels, vol. III, Londres, The Kibo Foundation, 1994, pp. 20-49.

Importante Collection d'Ivoires de la Chine et du Japon. Collection Eugène Sarlin (première vente), Hôtel Drouot, 5-9 de noviembre de 1923, París, 1923.

Importante Collection d'Ivoires de la Chine et du Japon. Collection Eugène Sarlin (deuxième vente), Hôtel Drouot, 19-21 de mayo de 1924, París, 1924.

Irvine, Gregory, Japanese cloisonné: the seven treasures, Londres, Victoria \& Albert publ., 2006.

Johnson, Deborah, "Japanese Prints in Europe before 1840", The Burlington Magazine, vol. 124, n. 951 , junio de 1982, pp. 343-348.

Kornicki, P. F., "Collecting Japanese Books in Europe from the Seventeenth to the Nineteenth Centuries", Bulletion of Portuguese/Japanese Studies, junio de 2004, vol. 8, pp. 21-38.

Lacambre, Geneviève, "Le Japon dans les collections publiques françaises", Le Japon Illustré. De Hokusai à l'École Utagawa, Musée des Beaux-Arts, Rouen, 2009, pp. 32-41.

Lindau, Rudolph, Un voyage autour du Japon, París, Librairie de L. Hachette et Cie., 1864.

Meissner, Kurt, Deutsche in Japan, 1639-1960, Tokio, Deutsche Gesellschaft für Natur und Völkerkunde Ostasiens, 1961.

Murray, John, A hand-book for travellers on the continent, London, 1840.

Premoli, Palmiro, L'Italia geografica illustrata, Milano, Sonzogno, 1891.

Roca, José, Barcelona en mano. Guía de Barcelona y sus alrededores, Barcelona, E. López, 1884.

The Illustrated London News, 4-II-1854, "Japanese exhibition", pp. 97-98.

The Japan Weekly Mail, 26-II-1870; 5-III-1870: 83; 11-I-1873: 26.

Van Gulik, Willem R., "Von Siebold and his Japanese Collection in Leiden", Leiden Oriental Connections, 1850-1940, Leiden, 1989a, pp. 378-391.

Van Gulik, Willem R., "Collecting for science", Imitation and inspiration. Japanese Influence on Dutch Art, Amsterdam, 1989b, pp. 75-81.

Wagner, Richard, Mi Vida, Barcelona, José Janés, 1952.

Weber, A.R., Kontorrock und konsulatsmütze, Tokio, Deutsche Gesellschaft für Natur und Völkerkunde Ostasiens, 1981.

Weisberg, Gabriel P., The Independent Critic. Philippe Burty and the visual arts of mid-nineteenth Century France, Peter Lang, New York, 1993.

Payno, Manuel, Barcelona y México en 1888 y 1889, Barcelona, Espasa, 1889.

Fecha de recepción: 25-I-2011

Fecha de aceptación: 5-IV-2011 